\title{
Different models of pharmaceutical services and care in primary healthcare clinics in the Eastern Cape, South Africa: Challenges and opportunities for pharmacy practice
}

\begin{tabular}{|c|c|}
\hline \multicolumn{2}{|c|}{$\begin{array}{l}\text { Authors: } \\
\text { Amy C. Bobbins }{ }^{1} \\
\text { Susan Burton } \\
\text { Teri-Lynne Fogarty }^{1}\end{array}$} \\
\hline \multicolumn{2}{|c|}{$\begin{array}{l}\text { Affiliations: } \\
{ }^{1} \text { Department of Pharmacy, } \\
\text { Faculty of Health Sciences, } \\
\text { Nelson Mandela University, } \\
\text { Port Elizabeth, South Africa }\end{array}$} \\
\hline \multicolumn{2}{|c|}{$\begin{array}{l}{ }^{2} \text { Pharmacy Practice Division, } \\
\text { Faculty of Pharmacy, Rhodes } \\
\text { University, Grahamstown, } \\
\text { South Africa }\end{array}$} \\
\hline \multicolumn{2}{|c|}{$\begin{array}{l}\text { Corresponding author: } \\
\text { Amy C. Bobbins, } \\
\text { amyclairebobbins@gmail.com }\end{array}$} \\
\hline \multicolumn{2}{|c|}{$\begin{array}{l}\text { Dates: } \\
\text { Received: } 14 \text { Dec. } 2019 \\
\text { Accepted: } 22 \text { Apr. } 2020 \\
\text { Published: } 27 \text { July } 2020\end{array}$} \\
\hline \multicolumn{2}{|c|}{$\begin{array}{l}\text { How to cite this article: } \\
\text { Bobbins AC, Burton S, } \\
\text { Fogarty TL. Different models } \\
\text { of pharmaceutical services } \\
\text { and care in primary } \\
\text { healthcare clinics in the } \\
\text { Eastern Cape, South Africa: } \\
\text { Challenges and opportunities } \\
\text { for pharmacy practice. Afr J } \\
\text { Prm Health Care Fam Med. } \\
\text { 2020;12(1), a2323. https:// } \\
\text { doi.org/10.4102/phcfm. } \\
\text { v12i1.2323 }\end{array}$} \\
\hline \multicolumn{2}{|c|}{$\begin{array}{l}\text { Copyright: } \\
\text { @ 2020. The Authors. } \\
\text { Licensee: AOSIS. This wc } \\
\text { is licensed under the } \\
\text { Creative Commons } \\
\text { Attribution License. }\end{array}$} \\
\hline \multicolumn{2}{|l|}{ Read online: } \\
\hline 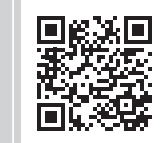 & $\begin{array}{l}\text { Scan this QR } \\
\text { code with your } \\
\text { smart phone or } \\
\text { mobile device } \\
\text { to read online. }\end{array}$ \\
\hline
\end{tabular}

Background: Primary health care (PHC) re-engineering forms a crucial part of South Africa's National Health Insurance (NHI), with pharmaceutical services and care being crucial to treatment outcomes. However, owing to a shortage of pharmacists within PHC clinics, taskshifting of the dispensing process to pharmacist's assistants and nurses is common practice. The implications of this task-shifting process on the provision of pharmaceutical services and care remains largely unstudied.

Aim: The study aimed to explore the pharmacist-based, pharmacist's assistant-based and nurse-based dispensing models within the PHC setting.

Setting: The Nelson Mandela Bay Health District, South Africa.

Methods: A mixed methods approach was utilised comprising of Phase 1: a pharmaceutical services audit to analyse pharmaceutical service provision and Phase 2: semi-structured interviews to describe the pharmaceutical care provision within each dispensing model thematically.

Results: Pharmaceutical services partially fulfilled minimum standards within all models, however, challenges exist that limit the quality of these services. Phase 2 showed that the provision of pharmaceutical care within all models was restricted by context-related constraints, thus patient-centred activities to underpin pharmaceutical services were limited.

Conclusion: Although pharmaceutical services may have been available for all models, compromised quality of these services impacted overall quality of care. Limited pharmaceutical care provision was evident within each dispensing model. The results raised concerns about the current utilisation of pharmacy personnel, including the pharmacist, within the PHC setting. Further opportunities exist, if constraints allow, for the pharmacist to contribute to better patient-centred care.

Keywords: primary health care re-engineering; pharmaceutical services; pharmaceutical care; dispensing models; task-shifting.

\section{Introduction}

Since 1994, South Africa has made progress towards a more equitable and united healthcare system for all South Africans, based on ideals of Universal Healthcare Coverage (UHC). These attempts have culminated in the implementation of the National Health Insurance (NHI), with primary health care (PHC) re-engineering being a major emphasis in the preparatory first phase of implementation. Considering South Africa's quadruple burden of disease (communicable diseases, non-communicable diseases, injuries and HIV), this reform justly aims to emphasise the strengthening of preventative and promotive PHC in conjunction with curative services..$^{1,2}$ Strengthening PHC, and its core principles of equity, affordability, effectiveness and efficiency, has been identified as an effective way of strengthening health systems in low- and middle-income countries (LMICs). ${ }^{2}$ Strengthening health systems aligned to PHC core principles promotes patient-centred health systems, providing care closer to patients aligned with social determinants of health. ${ }^{3,4}$

Thus, PHC strengthening initiatives have become of crucial importance to the health systems in many African countries and beyond. In South Africa, the revitalisation of PHC through the 
implementation of Operation Phakisa and the development of the Ideal Clinic (IC) concept, saw the growth in capacity and quality of health facilities with outreach and communitybased services. ${ }^{5}$ However, despite an increase in utilisation, disparities still existed, with inequalities prevalent; thus the NHI prioritised PHC during the first phase of implementation (2012/2013-2016/2017), with the aim of improving the quality of PHC aligned to the National Core Standards of the Office of Health Standards Compliance (OHSC). ${ }^{2,5}$

At all levels of healthcare, including PHC, pharmacotherapy is a frequently used intervention with the appropriate treatment regimen underpinning desired health outcomes. ${ }^{6}$ The knowledge of patient needs, medicine supply and a way of integrating both into safe, effective and appropriate medicine use is required. The pharmacist is ideally placed to support pharmacotherapy through the practice of pharmaceutical care that requires appropriate knowledge and training. Pharmaceutical care is a philosophy based on a patient-centred relationship, with the prioritisation of medicine-related needs and preferences that increase the quality of life of the patient. ${ }^{6,7}$ During the last 40 years, the pharmacy profession has experienced a shift to more cognitive, pharmaceutical care-related roles rather than one focused simply on medicine supply. Importantly, pharmaceutical care complements the principles of PHC, which aim at providing quality, patient-orientated care at the first level of contact of individuals. ${ }^{8,9,10}$

Pharmaceutical care is in contrast to pharmaceutical services as it is a philosophy involving the medicine needs of a patient and provision of the most appropriate medicinal therapy. The dispensing process is a part of pharmaceutical service provision, together with other integral services such as medicine supply management. Dispensing involves three phases including: interpretation and evaluation of a prescription (Phase 1), preparation and labelling of a prescribed medicine (Phase 2) and the provision of information and instructions to the patient (Phase 3). Notably, other than basic counselling on medicine use during Phase 3 of the dispensing process, dispensing offers no tangible patient-specific pharmaceutical care required for positive health outcomes. ${ }^{8}$ Pharmaceutical care involves thorough assessment of patient data, disease data and medicine-related data where patient-specific medicine-related problems are identified, including ineffective dosages, non-adherence, or Adverse Drug Reactions (ADRs). After identifying unmet medicine-related needs, a rational decision-making process follows to develop a prevention strategy for identified problem(s) and establishing a care plan with related interventions. Thereafter, follow-up of established interventions takes place to evaluate the outcome(s) versus the goal(s) of the individualised care plan. ${ }^{7}$

Having a full-time, on-site pharmacist has been presented as the ideal standard of pharmaceutical care provision at PHC facilities, yielding overall cost-saving for health systems. ${ }^{11,12}$ Currently, however, as a result of the shortage of pharmacists in the South African public sector, task-shifting to pharmacist's assistants and nurses has become common practice in PHC settings. ${ }^{13}$ Task-shifting, a common multidisciplinary phenomenon on the African continent, poses a pragmatic solution to better access and coverage of health service delivery as the demand for PHC increases. ${ }^{14,15}$

Task-shifting of pharmaceutical services has resulted in the emergence of three different dispensing models for the South African PHC. Larger PHC clinics may have an on-site pharmacist supervising pharmaceutical services provided by pharmacist's assistants, while also being involved in indirectly supervising pharmacist's assistants or nurses in surrounding clinics. In cases where pharmacists are not available on-site, post-basic pharmacist's assistants may be responsible for service provision while working under the indirect supervision of a pharmacist (up to five post-basic pharmacist's assistants supervised by one responsible pharmacist). The dispensing is restricted to quality standards stipulated by Good Pharmacy Practice (GPP). In many PHC clinics where pharmacists or pharmacist's assistants are not available, pharmaceutical services are provided by nurses who prescribe, dispense and manage medicine supply with the indirect support of a pharmacist or a pharmacist assistant. ${ }^{10}$ Notably however, effects of task-shifting of the dispensing process remains largely unstudied. ${ }^{16,17}$ There is a clear need for research into the impact of task-shifting on efficiency of service provision by contextual influencing factors, such as patient load, understaffing or insufficient infrastructure. ${ }^{18,19}$ Questions have been raised regarding PHC clinics where there is no on-site pharmacist to provide adequate pharmaceutical services and care, leaving dispensing practices misunderstood. ${ }^{20}$ In response to this identified research need, the primary aim of this study was to explore the different dispensing models at three public PHC clinics in the Nelson Mandela Bay Health District. These models included the pharmacist-based dispensing model (a pharmacist on-site with directly supervised pharmacist's assistants), the pharmacist's assistant-based dispensing model (with indirectly supervised post-basic pharmacist's assistants) and the nurse-based dispensing model. The effects of each model on the quality and availability of pharmaceutical services and the perceived quality of pharmaceutical care were studied, with challenges and opportunities relating to the functioning of PHC were identified.

\section{Method}

A two-phase, exploratory, mixed-methods study design (as summarised in Figure 1) was utilised to characterise the multifaceted phenomena affecting pharmaceutical services and care provision in each PHC clinic: Clinic N (nurse-based model), Clinic PA (pharmacist's assistant-based model) and Clinic P (pharmacist-based model).

\section{Setting}

The study took place at three PHC Clinics in the Nelson Mandela Bay District (Sub-District C) in the Eastern Cape 


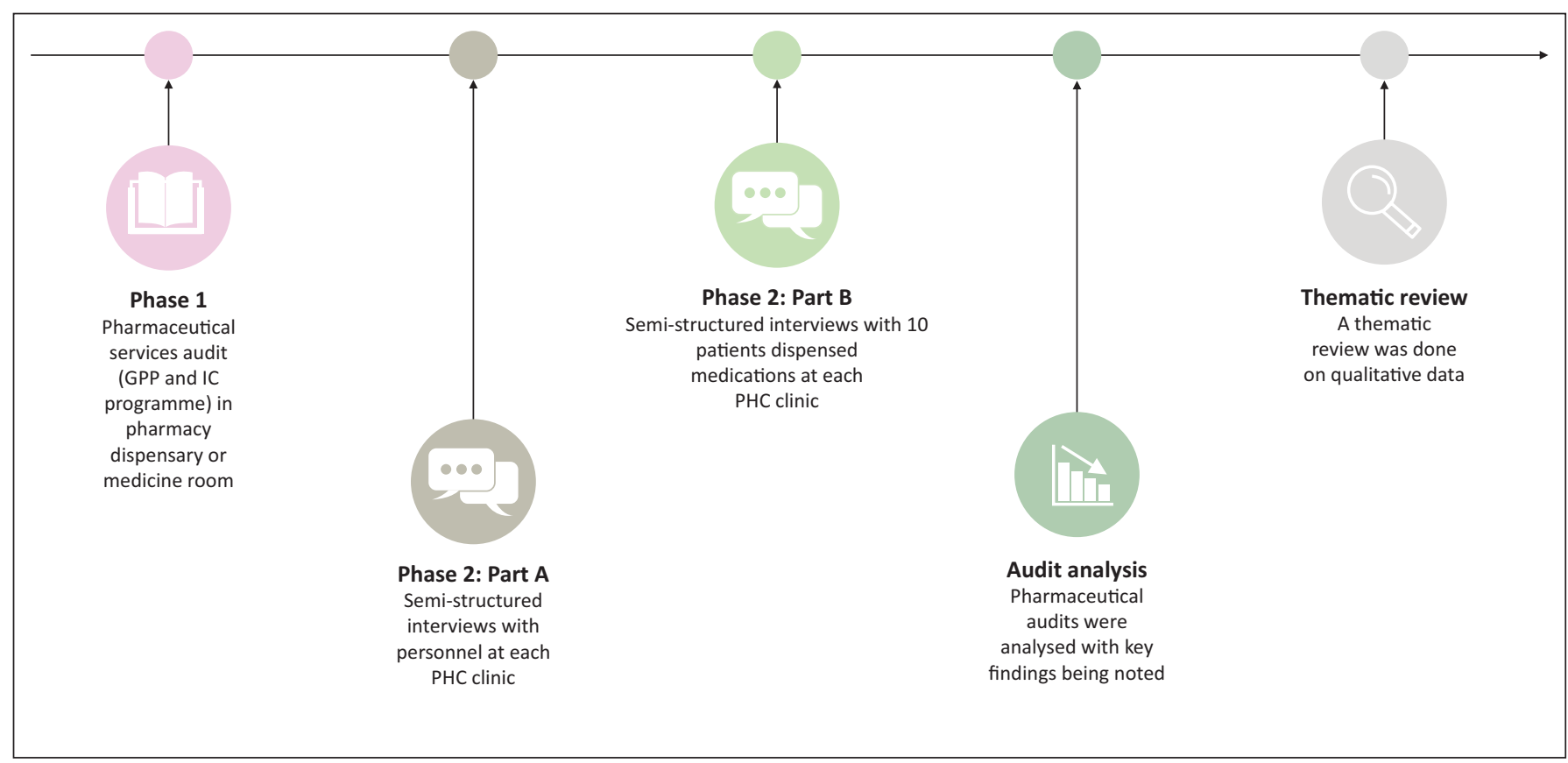

FIGURE 1: A chronological summary of the study design utilised.

Province of South Africa. ${ }^{21}$ Nelson Mandela Bay District is comprised of three sub-districts, namely Nelson Mandela A, Nelson Mandela B and Nelson Mandela C, and falls into socioeconomic quintile 5 with $20.7 \%$ medical aid scheme coverage. Within the district there are $39 \mathrm{PHC}$ clinics and 9 community health centres (CHCs) with an estimated 33.3\% considered ICs, complying with benchmark IC Core Standards. ${ }^{22,23}$ The Eastern Cape Province is a meaningful setting in which to conduct research related to health service delivery as the healthcare system has a noted history of poor service delivery, in urgent need of critical intervention. ${ }^{24}$

\section{Study design}

\section{Phase 1}

To provide insight into the quality and availability of pharmaceutical services at each PHC clinic, an audit checklist was compiled. The audit comprised a purpose-designed checklist, integrating aspects of relevant national guidelines; the IC Core Standards; GPP Minimum Standards as stipulated by the Pharmacy Act of 1974; and two checklists provided by the South African Pharmacy Council (SAPC). ${ }^{10,25,26}$ The GPP guidelines form a worthwhile tool in assessing the quality of pharmaceutical service provision at facility level, as wherever these services are provided, the GPP minimum standards should be upheld in practice. As the pharmaceutical services will take place in a PHC clinic context, the IC standards relating to the supply of medicines can also be used to determine the quality of pharmaceutical services provision from a $\mathrm{PHC}$ revitalisation reference point. All requirements, based on minimum standards, were checked off as 'yes/does comply' or 'no/does not comply', with all requirements allocated a numerical weighting (ranging from 1 - 'not important, but necessary to record', to 7 - 'extremely important') to indicate the importance of each requirement as devised by SAPC checklists.
The audit was compiled with two sections: 'general standards relating to the premises' where pharmaceutical services take place and 'general standards relating to the type of personnel present', with differing sections relating to the type of personnel dispensing at each facility, i.e. a nurse (in a medicine room), a pharmacist's assistant (in a pharmacy) and a pharmacist (in a pharmacy). Differing sections were necessary as the GPP standards differ depending on the personnel available to provide pharmaceutical services at a facility. If dispensing takes place by a nurse, there should be a suitable medicine room for medicine storage with dispensing taking place in nurses' consultation rooms, according to GPP standards. The GPP standards differ for a pharmacy, including whether a pharmacist is on-site or not, as other activities such as compounding or pre-packing of medications may take place in this setting. ${ }^{10}$

The completed audits were analysed by the researcher and totals were added up for each facility. Although no statistical analysis was done on the audit data, the data gave descriptive insight into the general availability and quality of pharmaceuticalservicesoffered ateachPHCclinic. Additionally, the review of data from Phase 1 was particularly important for Phase 2: Part A and Part B as it provided an opportunity for personnel to elaborate on any audit results that influenced the practice of pharmaceutical services and care at each facility. This speaks to the mixed-methods design of the study with its complementary nature providing synergistic insight relating to key findings..$^{27,28}$

In Phase 1 of the study, all PHC clinics in the Nelson Mandela Bay Health District made up the population of the study. Purposive non-probabilistic sampling was utilised, with three PHC clinics being selected from one sub-district of the Nelson Mandela Bay Health District as made 
available by the Department of Health. The three PHC clinics were selected on whether they have nurse-based, pharmacist's assistant-based or pharmacist-based dispensing models. Furthermore, for Phase 1, the inclusion criteria involved the ability to conduct the audits in areas (pharmacy or medicine room) where dispensing, storage and stock management of medicines dispensed at the clinics were carried out.

\section{Phase 2}

The lived experiences of personnel and patients of pharmaceutical care provision in the dispensing process were investigated in two parts. Firstly, Part A involved semistructured interviews with the dispensing personnel from each PHC clinic. Thereafter, Part B involved semi-structured interviews with 10 patients who received medication from the personnel at each clinic. This provided valuable insight into the dispensing process from both the dispensing personnel's and patients' perception.

For Phase 2: Part A of the study, inclusion criteria included being a pharmacist, nurse or post-basic pharmacist's assistant involved in the dispensing of medicines at the respective facilities. Exclusion criteria included any staff members who did not dispense medications to patients, as well as nurses facilitating Nurse-Initiated Management of Anti-retroviral Therapy (NIMART) at each PHC Clinic. Nurses dispensing anti-retroviral therapy (ART) certified as part of NIMART have received specialised training to dispense to patients with HIV. ${ }^{29}$ In Phase 2: Part A, the number of participants interviewed at each clinic was restricted by the number of people involved in the dispensing process. For Phase 2: Part $\mathrm{B}$, patients were required to have received dispensed medication at the respective PHC clinic to be eligible for inclusion in the study. Patients who had not had medications dispensed from the clinic were excluded from the sample. Patients who had their medications dispensed through the NIMART process were also excluded.

Each semi-structured interview during Part A and B lasted approximately 10-15 $\mathrm{min}$ and took place in a private area. Interviews were conducted in English, with an interpreter available during the interviews to translate questions or responses into IsiXhosa. This was helpful in promoting better insight into patients' experiences, as some of the participants could provide more articulate responses when speaking IsiXhosa. All interviews were audio-recorded and transcribed for consequent thematic analysis.

\section{Thematic analysis}

After collection and transcription of the recordings in Phase 2: Part A and B, the transcripts were imported and analysed using qualitative data analysis (QDA) software, Atlas.ti®. Firstly, inductive codes were allocated to parts of the transcripts that conveyed a particular analytical meaning. Thereafter, themes were developed from allocated codes that were categorised into groups of related meaning. Conceptual maps or network diagrams were then constructed as a means of graphically linking and relating code groups aiding the thematic analysis and theory building process. The thematic analysis process was independently reviewed for the less biased development of themes.

\section{Ethical consideration}

In the study, the audit and interviews were conducted away from other $\mathrm{PHC}$ clinic personnel and patients in a private area to prevent intimidation or harassment by other personnel orstaff.Furthermore, all responses were collected anonymously, with the identities of all participants remaining strictly confidential. Participants participated voluntarily in the audits (Phase 1) and the semi-structured-interviews (Phase 2). Before the study commenced, participants were informed of details of the voluntary nature of the research, including pertinent issues of confidentiality and anonymity of information provided. This was done through a printed written consent form, read by the participant and explained by the researcher for purposes of clarity. Once participants had understood and signed this consent form, informed consent of research participants was received before the commencement of interviews.

\section{Results}

\section{Phase 1}

Results from the audit, as displayed in Table 1, provide an indication of the compliance of each clinic with minimum standards of pharmaceutical services.

The results from Phase 1 indicated that Clinic $\mathrm{P}$ was the most compliant (79.9\%) with the minimum standards of the audit, with Clinic PA and Clinic N following thereafter with 71.5\% and $59.5 \%$ respectively. Results identified from the audit relating to crucial aspects of pharmaceutical services provision are mentioned below.

\section{Equipment and infrastructure}

All facilities had the required equipment to provide necessary services with no immediate concerns regarding medicine

TABLE 1: Results of the audit achieved by each clinic as part of Phase 1 of the study.

\begin{tabular}{|c|c|c|c|}
\hline Audit checklist section & $\begin{array}{l}\text { Achieved } \\
\text { score }\end{array}$ & $\begin{array}{l}\text { Maximum } \\
\text { score }\end{array}$ & Percentage \\
\hline \multicolumn{4}{|l|}{ Clinic $\mathbf{N}$} \\
\hline General standards relating to the premises & 341 & 537 & - \\
\hline $\begin{array}{l}\text { Standards relating to where the nurse } \\
\text { is the member of the personnel } \\
\text { (with a medicine room) }\end{array}$ & 54 & 126 & - \\
\hline Total & 395 & 663 & 59.5 \\
\hline \multicolumn{4}{|l|}{ Clinic PA } \\
\hline General standards relating to the premises & 411 & 537 & - \\
\hline $\begin{array}{l}\text { Standards relating to where the pharmacist } \\
\text { assistant (post-basic) is the member of the } \\
\text { personnel (with a pharmacy) }\end{array}$ & 72 & 138 & - \\
\hline Total & 483 & 675 & 71.5 \\
\hline \multicolumn{4}{|l|}{ Clinic P } \\
\hline General standards relating to the premises & 441 & 537 & - \\
\hline $\begin{array}{l}\text { Standards relating to where the } \\
\text { pharmacist is the main member of } \\
\text { the personnel (with a pharmacy) }\end{array}$ & 156 & 210 & - \\
\hline Total & 597 & 747 & 79.9 \\
\hline
\end{tabular}


storage and medicine integrity. The medicine rooms and dispensaries fulfilled most criteria on the pharmaceutical services audit integral to supporting pharmaceutical services at the facilities.

Although all three clinics provided service to patients partly as per minimum standards, some challenges were noted during Phase 1 that may have compromised the quality of services available. These challenges can be better understood with related responses in Phase 2 as they provide further clarification through lived experiences. These included:

- Poorly designed infrastructure, including small medicine room size and unrestricted access to medicines. For example, the medicine room in Clinic $\mathrm{N}$ was small and used as a kitchen for the clinic, meaning that the security of stored medicines was compromised.

The operational manager of Clinic $\mathrm{N}$ noted:

'My biggest challenge is the control or management [of medicines]. Let me put it this way, for example, if you can go there now and look at my pharmacy - it's not a pharmacy, it's a kitchen at the same time. So I can't say control of medication is not a challenge.' (Operational manager [Clinic N])

\section{Patient-related challenges}

Some challenges noted in Phase 1 limited the effectiveness of pharmaceutical services provided as patient motivation and attitude were often negatively affected:

- Although private consultation rooms were available in all clinics, these rooms are underutilised because of time constraints and a high patient load in Clinics P and PA. Both patients' and personnel's responses suggested that dispensing from a dispensing window, even if semiprivate, was not always conducive to adequate patient consultation:

'... We try and explain to the person and they will moan that you are taking time. It's always important to them to come and go quickly. So, if we see that this patient needs it, we call the patient in and explain everything so that you don't get the shout from the patients behind [them].' (Pharmacist's assistant 2 [Clinic P])

- With regard to patient record keeping, there was no computerised record keeping or dispensing taking place. Furthermore, pharmacy personnel in Clinic P expressed concern that there was no understanding between clinic staff regarding the system in place to manage patient folders. As a result, patient folders were often lost, incompletely stored or left at home, posing a challenge to providing services based on a complete patient history.

\section{Personnel-specific challenges}

The personnel dispensing medication reported some challenges that affected their ability to provide pharmaceutical services of the highest quality. These included:
- Concerns over the necessity for dispensing licences or appropriate permits within Clinic N. None of the nurses, except one nurse enrolled in the dispensing course at the time of the study, possessed said licences or permits.

- In relation to the above-mentioned, concerns were raised in Clinic $\mathrm{N}$ over the absence of prescription monitoring at the facility, since the diagnosis, prescribing and dispensing of medicines was provided by the same nurse. Thus, medication errors, interactions or health risks might go unnoticed. ${ }^{30,31}$ Where such discrepancies arose in Clinics P and PA, the pharmacist was considered better placed to intervene and, in collaboration with prescribers, to act to rectify the medicine-related problems encountered.

- Nurses and indirectly supervised pharmacy personnel expressed the need for more support from a pharmacist with regard to medicine supply management and dispensing. Although medicine stock-outs were reportedly not common within these three facilities, the need for regular pharmacist support with the management of supply of medicines was considered necessary for constant, reliable access to medicines.

\section{Phase 2}

Pharmaceutical services should ideally be accompanied by appropriate pharmaceutical care provision. Semi-structured interviews were conducted with personnel at each clinic (Phase 2: Part A) $(n=11)$ and with 10 patients who had received medicines from each clinic; (Phase 2: Part B) $(n=30)$ as per inclusion and exclusion criteria.

Table 2 states the types of personnel dispensing medicines who were interviewed as part of Phase 2: Part A of the study.

The key findings, as per the results of the qualitative data analysis, will be discussed according to the themes identified in Figure 2.

\section{Clinic-related challenges}

- Personnel, particularly in Clinic N, mentioned that patients did not use the PHC clinic system as intended. Patients reportedly bypass their local clinic or use multiple clinics as they prefer some facilities over others, owing to a perception of a difference in the quality of service delivery. This posed a challenge to providing quality services and care as it resulted in fluctuating

TABLE 2: Number of each type of personnel at each clinic interviewed in Phase 2: Part A of the study.

\begin{tabular}{lll}
\hline Clinic & Type of personnel & Number \\
\hline P & Pharmacist & 1 \\
& Pharmacist's assistant & 4 \\
N & $\begin{array}{l}\text { Operational manager } \\
\text { (registered nurse) }\end{array}$ & 1 \\
PA & Registered nurse & 3 \\
& Pharmacist's assistant & 2 \\
\hline
\end{tabular}




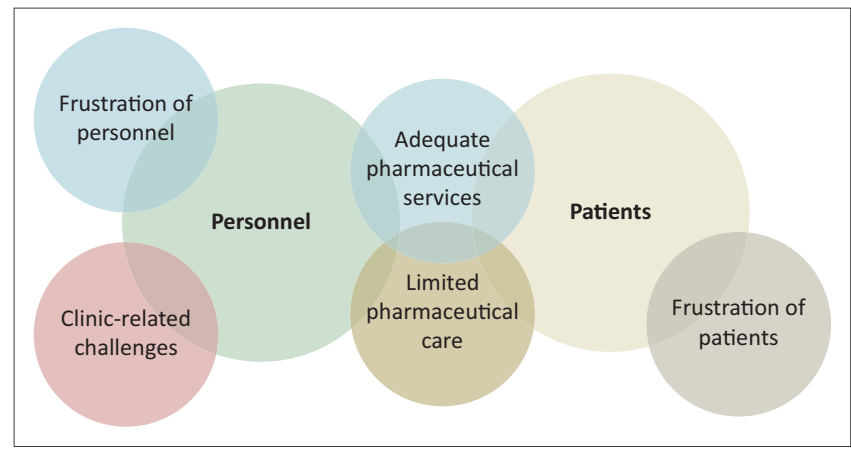

FIGURE 2: Themes identified from Phase 2: $\mathrm{A}$ and $\mathrm{B}$ of the study using qualitative data analysis.

medicine demand at clinics and difficulty in establishing a relationship with a patient with incomplete patient history or understanding of patient adherence.

\section{Frustrations of personnel}

Personnel noted frustrations that contributed to job dissatisfaction and fatigue, potentially negatively affecting the care provided to patients. Some frustrations noted were:

- Personnel, particularly the nurses (Clinic N), reported a high workload at all facilities, and dispensing services had to be incorporated into an already time-constrained patient consultation. Additionally, indirectly supervised pharmacist's assistants (Clinic PA) also expressed difficulty in fulfilling dispensing, pre-packing, stock management and prescription monitoring functions simultaneously at the clinic.

- In addition, personnel in all clinics noted staff shortages. Although this shortage may be attributed to a broader human resources deficit within the health sector, it resulted in increased pressure and frustration that may impact on the quality of services provided. For example, a pharmacist assistant stated the following:

'You know what, I like my job. But the problem is we are short staffed, so we are on our own. Like today we are short staffed, so it's too much for us. We are only two here for the whole clinic.' (Pharmacist's assistant 2 [Clinic PA])

\section{Frustration of patients}

- Patients at all clinics were concerned about long waiting times. The personnel in Clinic P were also aware that this is a clear cause of patient frustration that places stress on the pharmaceutical consultation and is a barrier to patient receptiveness:

'You know, we are like the shock absorbers. We are the last team to see the patient. If the patient gets angry starting from security, if they get angry there, with clerks, with nurses, it ends with us. They are already fighting when the situation is like that.' (Pharmacist's assistant [Clinic P])

\section{Adequate pharmaceutical services}

Patients at all clinics felt that the pharmaceutical services they received were adequate, fulfilling their medicine supply needs. Although there was satisfaction with the service provision, from both patient and personnel responses in all three clinics, it appeared that Phase 3 of the dispensing process (involving patient-specific medicine-related counselling) was not always provided to patients. Furthermore, many patients expressed the need for more in-depth medicine-related counselling.

\section{Limited pharmaceutical care}

Challenges to providing pharmaceutical care, including patient-centred activities involved in the pharmaceutical care development process, were noted at all three PHC clinics. These challenges included:

- The limited ability of the pharmacist to provide pharmaceutical care owing to a high administrative workload. When asked about his role at the on-site and indirectly supervised clinics, the pharmacist responded:

'My job description is, basically speaking, about 20\% dispensing and the rest is stock control and admin[istration] work, doing orders and checking orders.' (Pharmacist [Clinic P])

- At Clinic P, the pharmacist was viewed as an adjunctive provider of medicines and medicine-related information at both the clinic on-site and at indirectly supervised clinics. However, the doctors and nurses do not usually collaborate with the pharmacist as a multidisciplinary healthcare team (MDHT).

- Patient non-adherence was a major theme in all clinics, negatively impacting personnel motivation and the desired treatment outcomes of chronic therapy. When asked about challenges experienced at the dispensary, a pharmacist's assistant from Clinic P noted:

'The biggest one is that they are defaulting - I can say maybe it's $80 \%$ of patients that are defaulting, but I don't know why.' (Pharmacist's assistant 1. [Clinic P])

- With regard to Adverse Drug Reaction (ADR) monitoring, the pharmacist (Clinic P) in this study had the most knowledge regarding the process. However, he expressed disappointment regarding limited feedback of submitted ADR reports. Other dispensing personnel, in Clinics N and PA, had vague knowledge of ADR reporting, with little reporting happening from within these clinics.

\section{Discussion}

Phase 1 of the study found differing levels of compliance of the medicine room and pharmacies in relation to the minimum standard of pharmaceutical services delivery. In terms of service provision, minimum standards of service were partly upheld in all three PHC clinics; however, the ideal standard was compromised owing to existing challenges. Within the greater context of the $\mathrm{NHI}$ and the progressive realisation of access to quality health care, these challenges regarding pharmaceutical services may be of concern. ${ }^{2}$

Firstly, poor infrastructure and its effect on service provision was noted. Within Clinic N, the medicine room was used as a 
kitchen with unrestricted access. Although dispensing takes place from consultation rooms in Clinic $\mathrm{N}$, the exclusion of a medicine room up to security standards necessary to promote safe storage of medicines means that the mishandling or theft of medicines is a concern. Theft of medicines has been identified as a result of poor medicine supply and security thereof within the South African healthcare system. It promotes potential medicine stock-outs, resulting in medicine unavailability and compromised provision of pharmaceutical services. ${ }^{32}$

Additionally, at Clinics $\mathrm{P}$ and $\mathrm{PA}$, the infrastructure supporting patient consultation (in the form of dispensing windows) offered semi-private consultation. There was concern from both patients and personnel as patients felt their privacy was being compromised and that personnel could not properly counsel patients owing to limited time. Although adequate areas for private consultation were available in Clinics P and PA (as required as part of GPP standards), as a result of high patient load, they were often unused..$^{10}$ Andersen, Blenkinsopp and Armstrong ${ }^{33}$ note that privacy involves the ability to have a discussion within the pharmacy setting without being interrupted or overheard by other patients. As part of the dispensing process, providing medicine-related counselling in a private, comfortable setting promotes patient receptiveness and comfort, thus quality provision of pharmaceutical services. ${ }^{30}$ The use of a private consulting area is preferred by patients because of the increased privacy, which is important when dealing with conditions with associated stigma, such as HIV and/or AIDS. ${ }^{11}$ These spaces that allow for patient consultation are particularly important in terms of provision of pharmaceutical care as they affect patient receptiveness within the care relationship. Foster and McIntyre ${ }^{11}$ recommend putting up screens within the waiting areas to ensure privacy for patient counselling while dispensing with less interference from those in the waiting area. This could be a practical solution to preventing consultation interruption.

Some administrative concerns regarding service provision were noted, including inefficient record-keeping practices. In terms of inefficient record keeping, incomplete patient records or missing records were noted as a problem in the clinics. Full patient records are crucial to establishing any previously dispensed medicines and patient history. ${ }^{10}$ Furthermore, patient records can be used to inform knowledge of prescription patterns and common irrational prescribing trends, and can guide demand for medicines, aiding in preventing stock-outs. ${ }^{34}$ Thus, these crucial documents being lost or incomplete at the three clinics was a barrier to providing complete and informed pharmaceutical services. In addition, according to the IC Manual, dispensing processes at PHC clinics should be computerised as part of the District Health Information System (DHIS). ${ }^{35}$ Similarly, the GPP mentions that, if possible, dispensing processes and patient records should be computerised. ${ }^{10}$ At all three clinics there was no computerised system for dispensing, with manual dispensing taking place in each clinic. This observation appears to be in agreement with the situation throughout the country, with
Gray et al. ${ }^{31}$ noting that public sector facilities are more likely than private sector facilities to have paper-based dispensing and patient record systems in place.

Lastly, as no dispensing licences or appropriate permits were evident for the nurses involved in the study, concerns over the legal dispensing of medicines was raised. The National Drug Policy of 1996 states that health personnel should be issued with a dispensing licence by the South African Health Products Regulatory Authority (SAHPRA) proving their competency to dispense within particular geographical limits. ${ }^{36,37}$ However, according to the Medicines and Related Substances Act (101 of 1965), PHC nurses may be exempt from holding a licence in terms of section 22A (and section $22 \mathrm{C}[1][\mathrm{a}]$ ) if they hold a valid permit in terms of section 56[6] of the Nursing Act (Act 33 of 2005). ${ }^{38,39}$ This allows nurses to physically examine and diagnose patients, as well as to keep, supply, administer and prescribe medication for certain conditions in the absence of a doctor or pharmacist. ${ }^{39}$ Gray $^{37}$ notes that this should not be utilised as a long-term resolution and that developing suitable qualifications and regulations and amending the Schedules to the Medicines and Related Substances Act to support this provision are necessary when aiming at offering a full set of pharmaceutical services. Thus, better alignment between legislation and practice is required to promote safer and more effective task-shifting processes.

At Clinic N, the diagnosis, prescribing and dispensing of medicines for a patient consultation is provided by the same nurse. Even though permitted by the above provisions in legislation, research has shown that having the prescriber and personnel as the same person at a facility adds to the potential health risk of patients as the 'double checks' involved in prescription review (ensuring quality of the process) are bypassed. ${ }^{11,37}$ Thus, medication errors, interactions or health risks may go unnoticed during the provision of pharmaceutical service. Furthermore, the pharmacist's assistants may face similar challenges in prescription monitoring owing to limited knowledge regarding rational prescribing, medicine interactions or adverse effects. ${ }^{11,40}$ This corresponds to concerns raised in the study as both nurses and pharmacist assistants mentioned the need for more pharmacist support in dispensing activities.

Additionally, in both Clinics N and PA, the need for more support in medicine supply management was expressed. Crowley and Stellenberg ${ }^{41}$ state that because of nurses having an increased workload, they need to be adequately supported such that they can provide adequate pharmaceutical services for patients. Similarly, Osman ${ }^{40}$ notes that indirectly supervised pharmacist's assistants within PHC settings often find supply management challenging as a result of not having a firm grasp of supply management skills (involving ordering or budget utilisation). Furthermore, many indirectly supervised pharmacist's assistants, such as those at Clinic PA, are short staffed and lack computerised stock management software to aid with stock management. ${ }^{40}$ 
From Phase 2 of the study, from both patient and personnel responses, it would appear that Phase 3 of the dispensing process (involving medicine-related counselling) was often inadequate, rushed or left out of dispensing. ${ }^{10}$ However, most patients mentioned they were satisfied with the service as they had received a medicine. It appeared that the act of receiving a medicine at the clinic and the presence of no stock-outs fostered patient satisfaction with provision of pharmaceutical service. However, being provided with an understanding of the relevance and optimal use of the medicine appeared to be comparatively less important. In this regard, it seems patients are not familiar with having consultations with emphasis on their individualised medicine-related needs. Koster et al. ${ }^{42}$ note that patients often believe that they have received complete medicine-related information regarding medicine use; however, some information regarding specific instructions has often been left out of the consultation. Although the three phases of dispensing are defined clearly within the GPP manual, the enforcement of these phases (particularly Phase 3) within every dispensing consultation is not evident. ${ }^{10}$

The strengthening of $\mathrm{PHC}$ requires the optimisation of the roles of the current health workforce, in ways that enhance the service availability and quality. ${ }^{2,5}$ However, contextual constraints limited the ability of personnel to practise aspects of this care, such as high patient load and shortages of personnel within the clinics, together with patients not utilising the clinic system as intended. This high workload can hinder the provision of pharmaceutical care as it minimises provider performance and time available for the provision of care during consultation. ${ }^{43}$ High workload is of particular importance because of the consequential effects on clinic staff. Healthcare workers who face high workloads and exhaustion often have poor job satisfaction. Improving the workload of PHC staff (and causative factors, such as staff shortages) is essential to ensuring adequate retention of human resources and job satisfaction. ${ }^{44,45,46}$

Another barrier to the practice of pharmaceutical care was the administrative load of the pharmacist at Clinic P. The pharmacist, the professional best placed to practice pharmaceutical care, had a high administrative load of supporting pharmacist's assistants at the on-site clinic and at multiple indirectly supervised clinics that limited the amount of time spent on patient-orientated functions. ${ }^{7,8}$ Munroe et al. ${ }^{12}$ suggest that the pharmacist-based model should be the 'standard of care' as it has been shown to influence rational prescribing most appropriately, having clinical and cost-saving advantages. Effective task-shifting of this administrative load is necessary to free up the pharmacist for more cognitive, patient-centred activities. In resourceconstrained settings, pharmacists are still involved mostly in supply management, as this study confirmed. For example, to facilitate better task-shifting practice, medicine supply management needs to be facilitated by other pharmacy personnel, such that it frees up the pharmacist's time for pharmaceutical care ${ }^{9}$ Additionally, the pharmacist in Clinic $\mathrm{P}$ was underutilised in MDHT collaboration at PHC level. As a professional with valuable pharmacotherapeutic knowledge, particularly regarding patients with co-morbidities and associated polypharmacy, this underutilisation is a missed opportunity to improve patient care. ${ }^{1}$

Non-adherence, a medicine-related problem, was noted in all three clinics as a concern for dispensing personnel. Nonadherence is of particular concern in the PHC setting owing to the majority of regimens involving long-term chronic therapy. ${ }^{47,48}$ Pharmaceutical care has the ability to improve the adherence of patients through more patient-centred adherence monitoring. ${ }^{7}$ Furthermore, there are also opportunities for pharmacists to play a more decentralised mentorship role. For example, in a study in Lusikisiki within the Eastern Cape of South Africa, an adherence committee was set up to support an ART programme involving community members, clinic committee members, adherence counsellors and clinic staff, meeting monthly. ${ }^{49}$ This concept of an adherence committee including a pharmacist to track adherence and provide medicine-related support could be crucial to solving the problem of high non-adherence. In addition, the pharmacist could support and mentor clinic staff or community health workers (CHWs) on issues relating to adherence of chronic therapy and TB or ART management. ${ }^{1}$

In addition to adherence monitoring, ADR monitoring as part of pharmacovigilance, is a crucial aspect in promoting quality pharmaceutical care. However in the study, the only clinic to have knowledge of this monitoring was Clinic P with an on-site pharmacist. ${ }^{10}$ As with the response of the pharmacist at Clinic P, Suleman ${ }^{50}$ notes that South African health professionals often feel unmotivated to report ADRs appropriately due to poorly disseminated feedback data. This weak knowledge about the importance of ADR reporting in Clinics PA and N may negatively affect health outcomes and the safety of patient populations. ${ }^{51}$ Ideally, pharmacovigilance involves both medicine-related information and clinical knowledge, for example, drawing relationships between a medicine and a reported adverse event. Thus, a decentralised or mentorship role of a pharmacist best placed to combine both medicine-related information and clinical knowledge could see better understanding of medicine safety of differing personnel. This role could provide an opportunity for the pharmacist to advocate for patient safety better within the PHC context, contributing to better quality care and treatment outcomes. ${ }^{50}$

\section{Limitations}

The study took place at three PHC clinics of a sub-district within the Nelson Mandela Bay Health District. Thus, findings may contribute to the understanding of pharmaceutical services and care at the PHC level but cannot necessarily be generalised to other clinics in differing areas or provinces. 


\section{Recommendations}

Moving forward requires research, policy and practice changes through the collaboration of researchers, health professionals, policy-makers and patients to promote multidisciplinary and inclusive solutions. Some recommendations proposed from the study include the following.

\section{Task-shifting optimisation}

Task shifting of pharmacy personnel needs to be reconsidered in order to free-up the pharmacist for more patient-centred, cognitive functions. Additional training for pharmacist's assistants to grow in confidence and ability to execute administrative tasks, such as medicine supply management, should be provided. Optimal skills mix and guidance regarding task-shifting activities should consider the roles and contribution of each health professional in the provision of pharmaceutical services.

\section{Multidisciplinary team collaboration with PHC clinics}

Within the PHC MDHT, there needs to be a better understanding of pharmacists and their input in collaboration regarding patient care. Mechanisms by which the on-site pharmacist may be utilised more regarding pharmacotherapy of patients should be explored further. More emphasis on fostering this sense of multidisciplinary social capital within PHC clinics needs to be explored to maximise the contributions of all members of the healthcare team.

\section{Revised concept of pharmaceutical care}

Much has been understood about pharmaceutical care and the need for it in the PHC setting; $;^{11,12}$ however, the contextual limitations of facilities limit the ability to provide quality pharmaceutical care. Future policy needs to focus on these particular challenges within resource-constrained settings, providing practical solutions to executing aspects of pharmaceutical care, including a more decentralised, mentorship role of the pharmacist. Figure 3 indicates the suggested process of implementation of the recommendations aimed at utilising the health workforce within current settings, followed by appropriate policy discussion and research contribution to underpin these changes.

\section{Conclusion}

The results of the mixed-methods study indicated that pharmaceutical services partially fulfilled minimum standards with limited pharmaceutical care provision within each dispensing model. The results raised concerns regarding the efforts to improve PHC services under the NHI, as it indicates that there are still many challenges to providing optimal pharmaceutical services within this particular setting. The study also indicated that the current practice of task-shifting compromises the cognitive and collaborative role of the pharmacist, with further opportunities available for the pharmacist to contribute to better patient-centred roles within PHC.

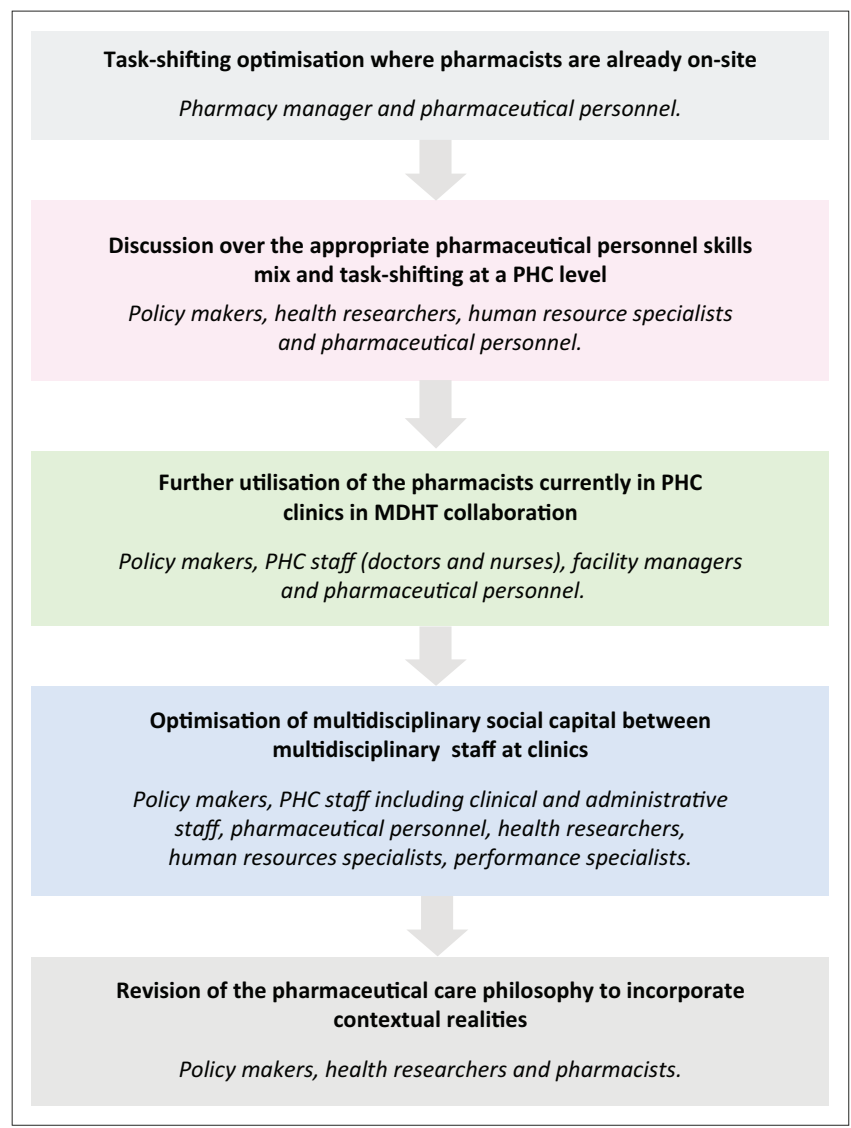

PHC, primary health care; MDHT, multidisciplinary healthcare team.

FIGURE 3: A suggested process of implementation of recommendations and examples of relevant stakeholders involved.

\section{Acknowledgements}

The authors are grateful to the personnel and patients of the PHC clinics who kindly participated in the study and to the Office of Research and Capacity Development of Nelson Mandela University for their financial support toward the completion of this work.

\section{Competing interests}

The authors have declared that no competing interest exists.

\section{Authors' contributions}

A.C.B was the primary researcher of the study and complied the first draft of the manuscript with review and assistance from S.B and T-L.F. S.B was the primary supervisor of the research and T-L.F. was the co-supervisor of the research.

\section{Funding information}

The study was funded by the Office of Research and Capacity Development, Nelson Mandela University.

\section{Data availability statement}

The data that support the findings of this study are available from the corresponding author, A.C.B, upon reasonable request. 


\section{Disclaimer}

The views and opinions expressed in this article are those of the authors and do not necessarily reflect the official policy or position of any affiliated agency of the authors.

\section{References}

1. Bheekie A, Bradley H. Re-engineering of South Africa's primary health care system: Where is the pharmacist? S Afr Fam Pract. 2016;58(6):242-248. https:// doi.org/10.1080/20786190.2016.1186365

2. Department of Health: South Africa. National Health Insurance for South Africa [document on the Internet]. vol. 41. Pretoria: Government Publishers; 2017 [cited 2019 Apr 30]. Available from: http://www.health.gov.za/index.php/nhi

3. World Health Organisation. The World Health Report 2008 - Primary health care (now more than ever) [document on the Internet]. Geneva: World Health
Organisation; 2008 [cited 2019 May 2]. Available from: https://www.who.int/ whr/2008/en/

4. World Health Organisation. Everybody's business: Strengthening health systems to improve health outcomes [document on the Internet]. Geneva: World Health Organisation; 2007 [cited 2019 May 1]. Available from: https://www.who.int/ Organisation; 2007 [cited 2019 May 1]. Available
healthsystems/strategy/everybodys business.pdf

5. Department of Health: South Africa. Operation Phakisa Ideal clinic realisation and maintenance final lab report [document on the Internet]. Pretoria: Government Printer; 2015 [cited 2018 July 23]. Retrieved from: https://www.idealclinic.org.za/ docs/2016/phakisa/Operation $\% 20$ Phakisa $\% 20$ Ideal $\% 20$ Clinic $\% 20$ Realisaation $\% 20$

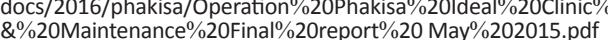

6. Cipolle RJ, Strand LM, Morley, PC. Pharmaceutical care practice: The patient centred approach to medication management services. 3rd ed. New York, NY: The McGraw-Hill Companies; 2012.

7. Hepler CD, Strand LM. Opportunities and responsibilities in pharmaceutical care. Am J Hosp Pharm.1990;47(3):533-543. https://doi.org/10.1093/ajhp/ 47.3.533

8. Wiedenmayer K, Summers RS, Mackle CA, Gous AGS, Everard M, Tromp D. Developing pharmacy practice: A focus on patient care handbook. Geneva: World Health Organisation, International Pharmacy Federation; 2006.

9. Walkowiak H, Keene D. Expanding the role of pharmacy staff in antiretrovira therapy. From the ground up. Washington, DC: Elizabeth Glaser Pediatric AIDS Foundation; 2014

10. South African Pharmacy Council. Good pharmacy practice in South Africa: Good pharmacy practice manual and associated SAPC rules. Pretoria: South African Pharmacy Council; 2018.

11. Foster N, Mclntyre D. Different models of pharmaceutical care in South Africa. Policy Brief. Health Economics Unit, School of Public Health and Family Medicine, University of Cape Town, Cape Town; 2011.

12. Munroe WP, Kunz K, Dalmady-Israel C, Potter L, Schonfeld WH. Economic evaluation of pharmacist involvement in disease management in a community pharmacy setting. Clin Ther. 1997;19(1):113-123. https://doi.org/10.1016/S01492918(97)80078-1

13. Gilbert L. Re-engineering the workforce to meet service needs: Exploring task shifting in South Africa in the context of HIV/AIDs and antiretroviral therapy. S Afr Sociol Rev. 2013;44(2):54-75. https://doi.org/10.1080/21528586.2013. 802537

14. World Health Organisation. Task shifting: Rational redistribution of tasks among health workforce teams: Global recommendations and guidelines [document on the Internet]. Geneva: World Health Organisation; 2007 [cited 2018 Sep 12] Available from: http://www.who.int/iris/handle/10665/43821

15. Dovlo D. Using mid-level cadres as substitutes for internationally mobile health professionals in Africa: A desk re-view. Hum Resour Health. 2004;2(1):7. https:// doi.org/10.1186/1478-4491-2-7

16. Monteith L, Grimwood A, Pillay K. Improve access of ART at the PHC leve through indirectly supervised pharmacist's assistants. Keth'Impilo: Cape Town 2010.

17. Sanne I, Orrell C, Fox MP, et al. Nurse versus doctor management of HIV infected patients receiving antiretroviral therapy (CIPRA-SA): A randomised noninferiority trial. The Lancet. 2010;376(9734):33-40. https://doi.org/10.1016/ S0140-6736(10)60894-X

18. Sello DA, Dambisya YM, Serfontein JHP, Lubbe MS. Factors influencing access to pharmaceutical services in underserviced areas of the West Rand District Gauteng Province, South Africa. Health SA Gesondheid. 2011;17(1):1-8. https:// doi.org/10.4102/hsag.v17i1.609

19. Fulton BD, Scheffler RM, Sparkes SP, Auh EY, Vujicic M, Soucat A. Health workforce skill mix and task shifting in low income countries: A review of recent evidence. Hum Resour Health. 2011;9(1):1. https://doi.org/10.1186/1478-4491-9-1

20. Hermann K, Van Damme W, Pariyo GW, et al. Community health workers for ART in sub-Saharan Africa: Learning from experience - capitalizing on new
opportunities. Hum Resour Health. 2009; $7(1): 31$. https://doi.org/10.1186/1478opportunities.

21. Department of Health: Province of the Eastern Cape. Annual Performance Plan 2018/2019 [document on the Internet]. Bhisho: Government Publishers; 2018 [cited 2018 Apr 16]. Available from: www.ehealth.gov.za/index.php/ 2018 [cited 2018 Apr 16]. Available from: www.ehealth.gov.za/index.php/ plan-2018-2019
22. Health Systems Trust. District Health Barometer 2016/2017 [document on the Internet]. Health Systems Trust: Durban; 2017 [cited 2018 May 18]. Available from: www.hst.org.za/publications/Pages/Distric-Health-Barometer-201617. aspx

23. Health Systems Trust. District Health Barometer 2017/2018 [document on the Internet]. Health Systems Trust: Durban; 2018 [cited 2019 Sep 29]. Available from: https://www.hst.org.za/publications/Pages/DHB20172018.aspx

24. Treatment Action Campaign. State of Provincial Healthcare System: Spotlight on Eastern Cape [homepage on the Internet]. 2018 [updated 2018 June 28; cited 2019 Sep 29]. Available from: https://tac.org.za/news/eastern-cape-state-ofhealth/

25. Department of Health: South Africa. Ideal Clinic Manual, Version 17 [document on the Internet]. Pretoria: Government Publishers; 2017 [cited 2018 July 23] Available from: https://www.idealclinic.org.za/docs/v17/Final\%20ldeal\%20 Clinic\%20Manual\%20-\%20version\%2017.pdf

26. The Pharmacy Act (No. 35 of 1974), as amended, South Africa. Pretoria: Government Printers; 1974

27. Creswell J, Clark VLP. Designing and conducting mixed methods research Thousand Oaks, CA: Sage; 2011.

28. Curry L, Nunez-Smith M. Mixed methods in health sciences research: A practical primer. Thousand Oaks, CA: Sage; 2015.

29. Department of Health: Province of KwaZulu-Natal. Nurse initiated management of Antiretroviral Therapy (NIMART) - 'The KZN Success Story' [document on the Internet]. Paper presented at the Provincial Council on AIDS; 2016 [cited 2018 Sep 15]. Available from: www.kznhealth.gov.za/PCA/3.2NIMARTDOcumentationPCAfinal.pdf

30. Kerr S. Using medicines wisely: The medicines information pharmacist's role. Hospital Pharmacist [serial online]. 2009 [cited 2019 Sep 24];9:164. Available from: https://www.pharmaceutical-journal.com/learning/learningarticle/ using-medicines-wisely-themedicinesinformationpharmacistsrole/10976343. article

31. Gray A, Riddin J, Jugathpal J. Health care and pharmacy practice in South Africa. Can J Hosp Pharm. 2016;69(1):36-41. https://doi.org/10.4212/cjhp.v69i1.1521

32. Bateman C. Drug stock-outs: Inept supply-chain management and corruption. S Afr Med J [serial online]. 2003 [cited 2020 Mar 14];103(9):600-602. Available from: http://www.samj.org.za/index.php/samj/article/view/7332/5311

33. Andersen C, Blenkinsopp A, Armstrong M. Feedback from community pharmacy users on the contribution of community pharmacy to improving the public's health: A systematic review of the peer reviewed and non-peer reviewed literature 1990-2002. Health Expect. 2004;7(3):191-202. https://doi.org/10.1111/j.13697625.2004.00274.x

34. Walker R. Pharmaceutical public health: The end of pharmaceutical care? Pharmaceut J [serial online]. 2000 [cited 2018 Mar 27];264(7085):340-341. Available from: https://www.pharmaceutical-journal.com/pharmaceutical-publichealth-the-end-of-pharmaceuticalcare/20000598.article?firstPass=false

35. Department of Health: South Africa. Ideal Clinic Definitions, Components and Checklists [document on the Internet]. Pretoria: Government Publishers; 2018 [cited 2019 Jun 23]. Available from: https://www.idealhealthfacility.org.za/docs/ v18/Final\%20ldeal\%20Clinic\%20Framework\%20-\%20version\%2018\%20(26\%20 July\%202018).pdf

36. Department of Health: South Africa. National Drug Policy for South Africa. Pretoria: Government Publishers; 1996.

37. Gray A. Prescribing and dispensing by nurses: Neglected steps in the legislative process. HIV Nursing Matters [serial online]. 2010 [cited 2019 May 3];1:28-31. Available from: http://sahivsoc.org/Files/nursing_magazine_sept_2010.pdf

38. Medicines and Related Substances Act (No. 101 of 1965), as amended, South Africa. Pretoria: Government Printer; 1965.

39. The Nursing Act (No. 33 of 2005), South Africa. Pretoria: Government Printer; 2005

40. Osman L. The challenge of indirect supervision. South African Pharmacist's Assistant . 2005;5(2):4.

41. Crowley T, Stellenberg EL. An evaluation of the adequacy of pharmaceutical services for the provision of antiretroviral treatment in primary health care clinics. Health SA Gesondheid. 2015;20(1):83-90. https://doi.org/10.1016/j. hsag.2015.02.004

42. Koster E, Blom L, Overbeeke M, et al. Quality of pharmaceutical care at the pharmacy counter: Patients' experiences versus video observation. Patient Prefer Adher. 2016;10:363-369. https://doi.org/10.2147/PPA.S102032

43. Perzynski A, Caron A, Margolius D, Sudano J. Primary care practice workplace social capital: A potential secret sauce for improved staff well-being and patient experience. J Patient Ex;2018:6(1):72-80. https://doi.org/10.1177/2374373518777742

44. Choi S-P, Cheung K. Pang, S-C. Attributes of nursing work environment as predictors of registered nurses' job satisfaction and intention to leave. J Nurs Manage.2013;21(3):429-439.https://doi.org/10.1111/j.1365-2834.2012.01415.x

45. Darwish A. Organisational commitment: A mediator of the relationships of leadership behaviour with job satisfaction and performance in a non-western country. J Manage Psychol. 2000;15(1):6-24. https://doi.org/10.1108/02683940010305270

46. Shaver K, Lacey L. Job and career satisfaction among staff nurses: Effects of job setting and environment. J Nurs Admin. 2003;33:166-172. https://doi.org/10.1108/ 02683940010305270

47. Fischer M, Stedman M, Lii J, et al. Primary medication non-adherence: Analysis of 195930 electronic prescriptions. Soc Gen Intern Med. 2010;25(4):284-290. https://doi.org/10.1007/s11606-010-1253-9 
48. World Health Organisation. Adherence to long-term therapies - Evidence for action [document on the Internet]. Geneva: World Health Organisation; 2013 [cited 2018 July 3]. Available from: http://whqlibdoc.who.int/publications/2003/9241545992.pdf

49. Médecins Sans Frontières South Africa. Achieving and sustaining universal access to antiretrovirals in rural areas: The primary health care approach to HIV services in Lusikisiki, Eastern Cape. Cape Town: Department of Health, South Africa; 2006.
50. Suleman F. Pharmacovigilance - Who should be responsible and why should we care? S Afr Pharm J. 2010;77(9):56-58.

51. Ruud KW, Srinivas SC, Toverud EL. Healthcare providers' experiences with adverse drug reactions and adherence challenges in antiretroviral therapy of HIV patients
in the Eastern Cape Province. Eur J Clin Pharmacol. 2012;68:1321-1328. https:// doi.org/10.1007/s00228-012-1254-1 